\title{
Testing of Polymeric Hollow Fibre Heat Exchanger with Crossed Hollow Fibres
}

\author{
Erik Bartuli ${ }^{1}$, Tereza Kroulikova ${ }^{1}$ \\ ${ }^{1}$ Heat Transfer and Fluid Flow Laboratory/Brno University of Technology \\ Technicka 2896/2, 61669 Brno, Czech Republic \\ Erik.Bartuli1@vut.cz; Tereza.Kroulikova@vut.cz
}

\begin{abstract}
The results of the development and experimental investigation of a polymeric hollow fibre heat exchanger are presented. A heat exchanger of a shell-and-tube type with an outer diameter of $80 \mathrm{~mm}$ and a length of $350 \mathrm{~mm}$ containing $2200206 \mathrm{~mm}-10$ ng polyamide hollow fibres with an outer diameter of $0.8 \mathrm{~mm}$ cross-wound at an angle to the axis of the heat exchanger. Cross-winding was realized with the help of the modified winding system X-Winder. Cold water with a temperature of $13^{\circ} \mathrm{C}$ and a constant flow rate of $21601 / \mathrm{h}$ was fed through the hollow fibres. The dependences of heat transfer characteristics on the shell fluid temperature and fluid flow rate are presented. The device was able to transfer $38 \mathrm{~kW}$ at a shell water temperature of $70^{\circ} \mathrm{C}$ and a shell fluid flow rate of $8001 / \mathrm{h}$. In these conditions, the maximum overall heat transfer coefficient reaches $1950 \mathrm{~W} / \mathrm{m}^{2} \mathrm{~K}$.
\end{abstract}

Keywords: Hollow fibre; Heat exchanger; Heat transfer coefficient; Polymeric hollow fibre heat exchanger.

\section{Introduction}

Despite all the advantages of metal heat exchangers, there are areas of application where due to a number of restrictions (weight, aggressive environment, impossibility of shaping, etc.) metal heat exchangers cannot be used. In these cases, a large role is played by heat exchangers made from non-metallic materials and in particular by polymeric heat exchangers.

Polymeric hollow fibre heat exchangers (PHFHE) are a relatively new type of polymeric heat exchanger [1]. This heat exchanger utilizes polymeric microchannels as the heat transfer surface. The outer diameter of these microchannels is less than $1 \mathrm{~mm}$ and has a wall thickness of about $0.1 \mathrm{~mm}$. The heat exchanger is made of thousands of such fibres. Despite the low thermal conductivity of polymeric materials [2], a thin wall and a large heat transfer area comparing with heat exchanger dimensions leads to a good thermal performance of the PHFHEs.

Due to the corrosive-resistant features, polymeric heat exchangers can be used in aggressive media, for example in the chemical industry. Jia et al. [3] presented an experimental study on the heat transfer performance of wet flue gas heat recovery system using a plastic longitudinal spiral plate heat exchanger. PHFHE can be also used for solving water desalination problems [4], [5].

It should be noted that the production of polymeric heat exchangers uses much less energy than the production of metal ones. The other significant advantages of plastic heat exchangers are their low weight, smooth surface, simplicity of shaping and producing, and resistance to fouling.

All these features allow PHFHE to compete on an equal footing with metal heat exchangers. PHFHE can be applied in such fields as heat recovery systems [6], evaporative cooling systems, desiccant cooling systems, and electronic device cooling [7], [8]. Also, PHFHEs with a membrane polymeric hollow fibers can be applied for filtration processes, chemical separation or medical treatment [9-11]. Most commercially available polymer heat exchangers can be used in low temperature applications.

\section{Experimental Section}

A hollow fibre heat exchanger of the shell-and-tube type was tested in the framework of this paper. The PHFHE was wound with the help of the modified winding system X-Winder. The heat exchanger consists of $2200206 \mathrm{~mm}-l$ long polyamide hollow fibres with an outer diameter of $0.8 \mathrm{~mm}$, which were cross-wound at an angle of $22.5^{\circ}$ to the axis of the heat exchanger. The inner structure of the PHFHE is shown in Fig. 1. 


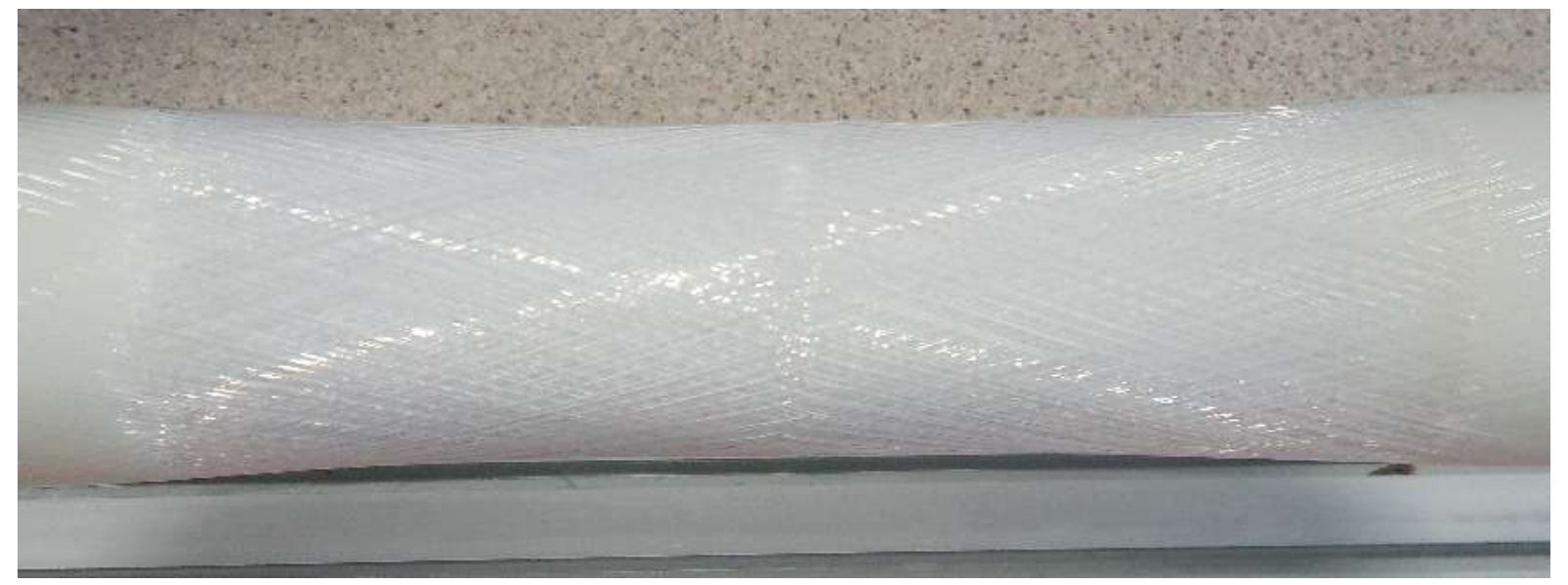

Fig. 1: Cross-wound hollow fibres inside the PHFHE.

A heat exchanger shell was made of glass fibre and was wound in several layers directly onto polymer hollow fibres. The outer diameter of the heat exchanger shell was $80 \mathrm{~mm}$, and the length was $350 \mathrm{~mm}$. Side flanges made of glass fibre had two holes for water input and output. A general view of the device is presented in Fig. 2. Despite the relative compactness of the device, the heat transfer area of the PHFHE was $1.14 \mathrm{~m}^{2}$.

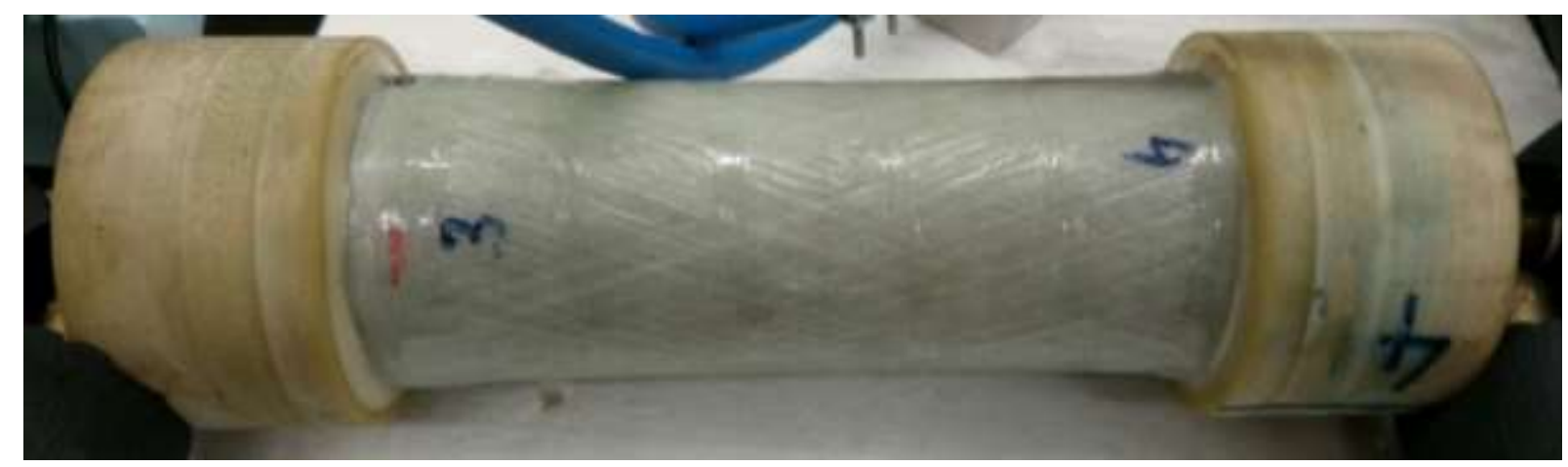

Fig. 2: General view of the tested PHFHE.

The experiments were carried out under the following conditions: cold water with a temperature of $13^{\circ} \mathrm{C}$ flows inside hollow fibres with a constant flow rate of $21601 / \mathrm{h}$. From the outer surface, in the heat exchanger shell, hot water flows. Experiments were carried out at two shell fluid temperatures $-70^{\circ} \mathrm{C}$ and $50^{\circ} \mathrm{C}$, while the shell fluid flow rate varied from 3901/h to $8001 / \mathrm{h}$ with a step of $2001 / \mathrm{h}$.

During the test, temperatures at the inlet and outlet of the heat exchanger shell, as well as at the inlet and outlet of the fibres, were measured. Pt100 resistance thermometers installed inside the water inlet and outlet channels were used, which makes it possible to achieve a measurement error of $+/-0.1^{\circ} \mathrm{C}$. The general view of the experimental setup is shown in Fig. 3, where 1 is the heat exchanger itself, 2 the inlet and outlet of hot water into the heat exchanger shell, 3 is the inlet of cold water that flows inside the fibres, and 4 is the outlet of cold water that flows inside the fibres. 


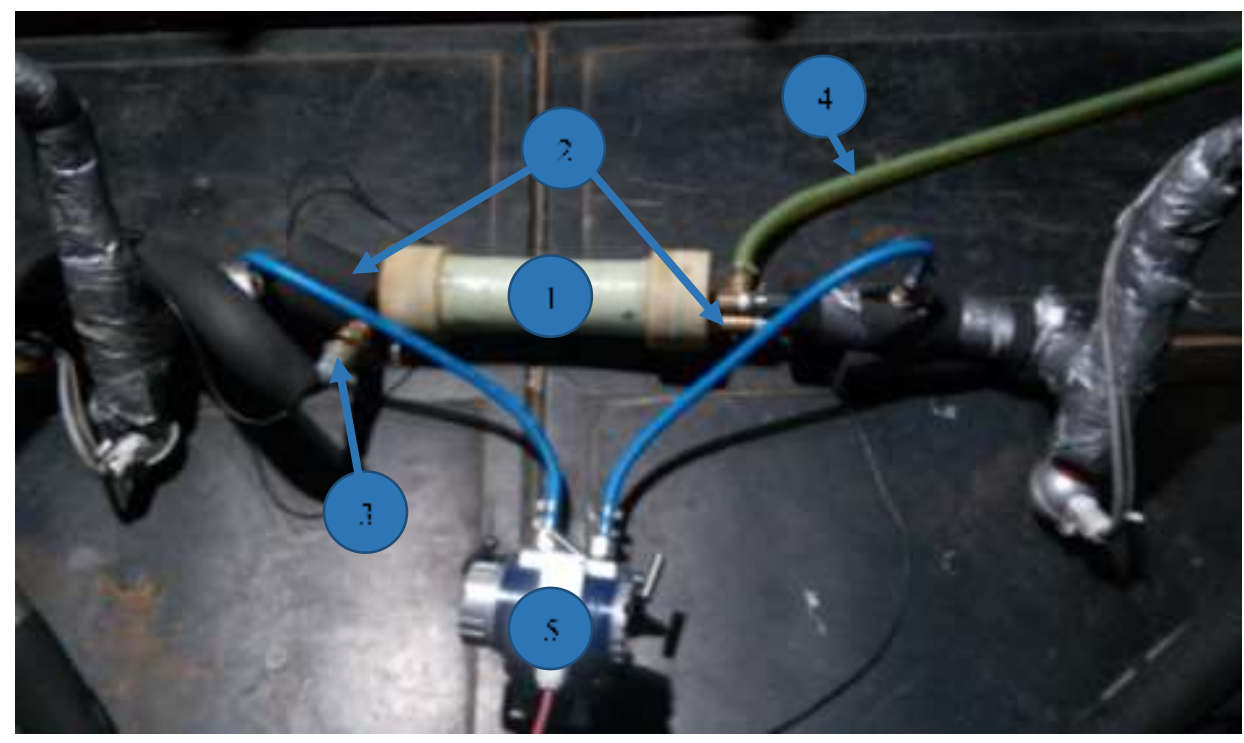

Fig. 3: General view of the experimental setup.

\section{Results and Discussion}

A differential manometer, marked in Fig. 3 as number 5, was used to measure the pressure drop inside the heat exchanger shell. The dependence of the pressure drop inside the heat exchanger on the shell fluid flow rate is shown in Fig. 4.

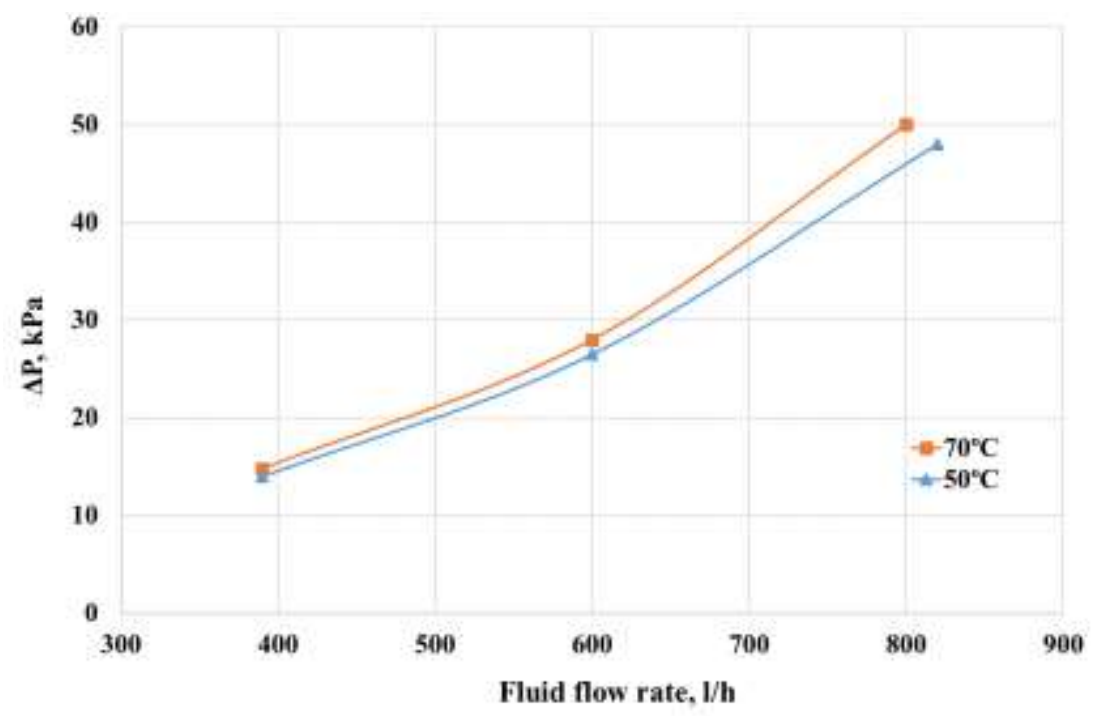

Fig. 4: Dependence of the pressure drop inside the PHFHE on the shell fluid flow rate.

It can be seen that the pressure drop is almost uninfluenced by the temperature of the liquid inside the fibres and reaches a value of 0.5 bar at a maximum shell fluid flow rate of $8001 / \mathrm{h}$. This is an acceptable value for shell-and-tube heat exchangers. It should be noted that inside the shell of the PHFHE tested there are a large amount of fibres. When the modified winding system X-Winder is used the number of fibres inside the heat exchanger can easily be decreased to achieve the optimal number for each application. 
Fig. 5 shows the dependence of the PHFHE heat transfer capacity on the shell fluid flow rate. Curves are given for shell water temperatures of $50^{\circ} \mathrm{C}$ and $70^{\circ} \mathrm{C}$. The difference in heat transfer capacity values for both water temperatures is about $27 \%$. The maximum reached at a shell water temperature of $70^{\circ} \mathrm{C}$ is $38 \mathrm{~kW}$ at a shell fluid flow rate of $8001 / \mathrm{h}$.

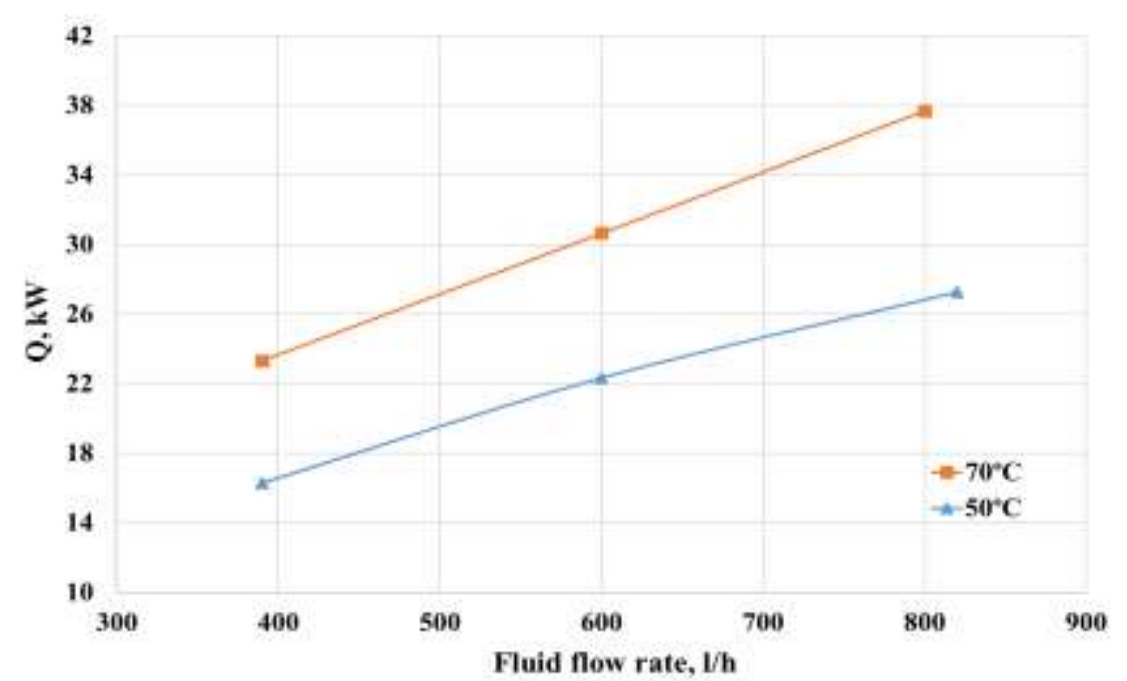

Fig. 5: Dependence of the heat transfer capacity of the PHFHE on the shell fluid flow rate.

Fig. 6 shows the dependence of the PHFHE overall heat transfer coefficient on the shell fluid flow rate. It can be seen that heat transfer coefficients do not depend on water temperature and reach a maximum value of $1950 \mathrm{~W} / \mathrm{m}^{2} \mathrm{~K}$ at a maximum shell fluid flow rate of $8001 / h$. This is a relatively high value. Hollow fibres crossing inside the shell lead to better shell fluid intermixing and allow us to achieve high heat transfer coefficients on the outer surface of hollow fibres.

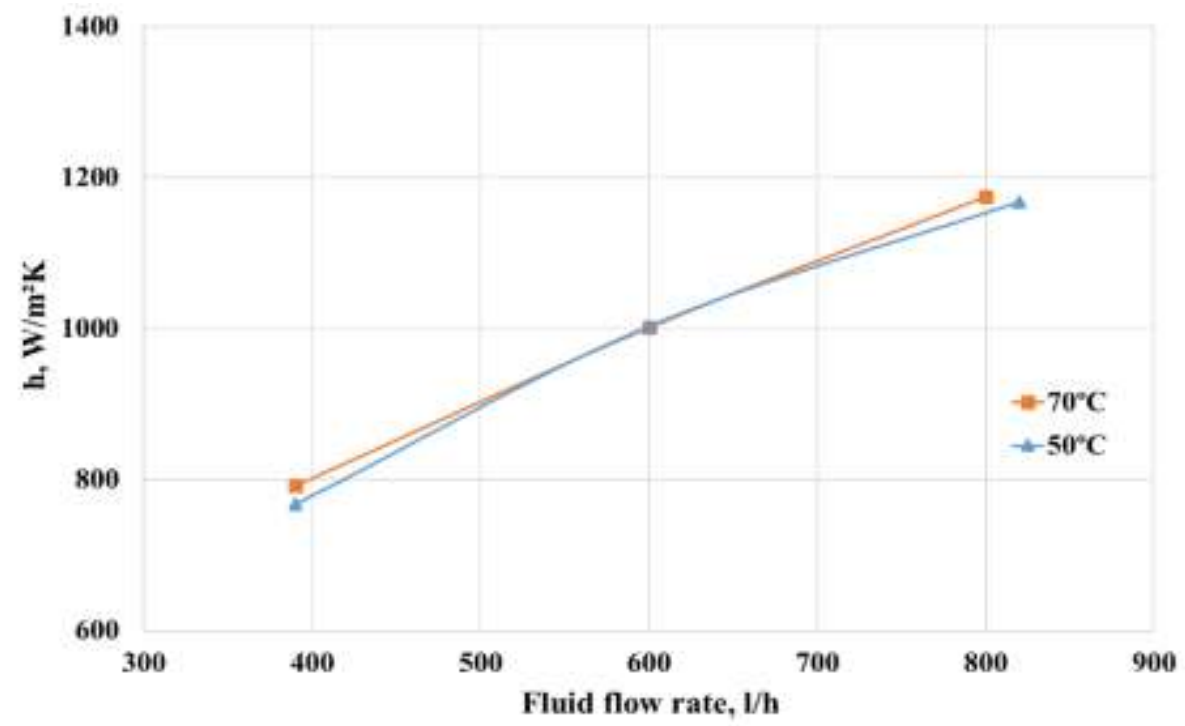

Fig. 5: Dependence of the overall heat transfer coefficient of the PHFHE on the shell fluid flow rate. 


\section{Conclusion}

The polymeric hollow fibre heat exchanger of a shell-and-tube type produced by winding technology was tested. PHFHE PHFHE had an outer diameter of $80 \mathrm{~mm}$ and a length of $350 \mathrm{~mm}$. At relative compactness, the PHFHE has a large heat transfer transfer area of $1.14 \mathrm{~m}^{2}$ that leads to a high heat transfer performance.

Tests were carried out at a cold-water flow inside hollow fibres with a temperature of $13^{\circ} \mathrm{C}$ and a constant flow rate of $21601 / \mathrm{h}$. From the outer surface, in the heat exchanger shell, hot water with temperatures of $50^{\circ} \mathrm{C}$ and $70^{\circ} \mathrm{C}$ was used and its flow rate varied from $3901 / \mathrm{h}$ to $8001 / \mathrm{h}$ with a step of $2001 / \mathrm{h}$.

The PHFHE showed good thermal performance. The device was able to transfer $38 \mathrm{~kW}$ at a shell water temperature of $70^{\circ} \mathrm{C}$ and a shell fluid flow rate of $8001 / \mathrm{h}$. In these conditions, the maximum overall heat transfer coefficient reaches $1950 \mathrm{~W} / \mathrm{m}^{2} \mathrm{~K}$.

\section{Acknowledgements}

This work was supported by the Ministry of Education, Youth and Sports of the Czech Republic under OP RDE grant number CZ.02.1.01/0.0/0.0/16_019/0000753 "Research centre for low-carbon energy technologies".

\section{References}

[1] D. M. Zarkadas and K. K. Sirkar, "Polymeric hollow fiber heat exchangers: an alternative for lower temperature applications," Ind. Eng. Chem. Res., vol. 43, no. 25, pp. 8093-8106, 2004.

[2] K. Weiß, I. Astrouski, M. Reppich and M. Raudensky, "Polymeric hollow-fiber bundles as immersed heat exchangers," Chem. Eng. Technol., vol. 41, no. 7, pp. 1457-1465, 2018.

[3] L. Jia, X. Peng, J. Sun, T. Chen, "An Experimental study on vapor condensation of wet flue gas in a plastic heat exchanger", Heat Transfer-Asian Research, vol. 30, no. 7, pp. 571-580, 2001.

[4] T. Brozova, M. Raudensky, E. Bartuli, E. Sladka, M. Dohnal, Membrane distillation module, Brno University of Technology, Brno, CZ ZENA s.r.o., Ostopovice, CZ: i. 32427, utility model, 2018.

[5] T. Brozova and M. Raudensky, "Determination of surface wettability of polymeric hollow fibres," J. Elastomers Plast., vol. 50, no. 8, pp. 737-746, 2018.

[6] J. Hejcik, P. Charvat, L. Klimeš and I. Astrouski, “A PCM-water heat exchanger with polymeric hollow fibres for latent heat thermal energy storage: a parametric study of discharging stage," J. Theor. App. Mech.-Pol., vol. 54, no. 4, pp. 1285-1295, 2016.

[7] M. Schmidt, I. Astrouski, M. Reppich and M. Raudensky, "Solar panel cooling system with hollow fibres," Appl. Sol. Energ., vol. 52, no. 2, pp. 86-92, 2016.

[8] M. Raudensky, I. Astrouski, T. Brozova and E. Bartuli, "Flexible polymeric hollow fiber heat exchangers for electronic systems," in 2016 15th IEEE Intersociety Conference on Thermal and Thermomechanical Phenomena in Electronic Systems, Las Vegas, NV, pp. 1143-1147, 2016.

[9] P. Bulejko, M. Dohnal, J. Pospisil, et al., "Air filtration performance of symmetric polypropylene hollow-fibre membranes for nanoparticle removal," Sep. Purif. Technol., vol. 197, pp. 122-128, 2018.

[10] T. Sverak, P. Bulejko, J. Ostrezi, et al., "Separation of gaseous air pollutants using membrane contactors," in Proceedings of 1st International Conference on Advances in Environmental Engineering, Ostrava, CZ, 2017, vol. 92, pp. 1-6.

[11] P. Bulejko, V. Adamec, R. Skeřil, B. Schüllerová and V. Bencko. "Levels and Health Risk Assessment of PM 10 Aerosol in Brno, Czech Republic," Cent. Eur. J. Public Health, vol. 25, no. 2, pp. 129-134, 2017. 